\title{
Living Persona Technique applied to HCI Education
}

\author{
Bruno Warin \\ Laboratory LISIC \\ University Littoral Côte d'Opale \\ F-62100 Calais, France \\ bruno.warin@univ-littoral.fr
}

\author{
Christophe Kolski \\ LAMIH-UM CNRS 8201 \\ University Valenciennes and \\ Hainaut-Cambrésis \\ F-59313 Valenciennes, France \\ christophe.kolski@univ- \\ valenciennes.fr
}

\author{
Claudine Toffolon \\ Laboratory LIUM \\ University of Maine \\ F-72085 Le Mans, France \\ claudine.piau.toffolon@univ- \\ lemans.fr
}

\begin{abstract}
This paper aims to present an experience report on a new pedagogical technique which applies to the teaching of interactive systems: the Living Persona technique. First, we review the well-known technique of Persona that is used in some processes of realization of interactive systems. In this technique, a Persona represents an archetype of the users interacting in the system to be produced. From this Persona technique, we define the Living Persona one. Within the framework of practical work students have to specify an interactive system, this technique of Living Persona consists in making the teacher play the role of a representative of the contracting authority, who is also potentially a future user of the system to be specified. As a consequence, during his meetings with the students, the teacher has to adopt a behavior in compliance with the state of mind of the users' archetype defined by the Persona. Then we present a pedagogical scenario which integrates this Living Persona technique and we apply it to a practical work in which the students must produce an interactive system specification using the Unified Modeling Language (UML). We show through a classroom experience that the practical work set up provides students with work situations close to professional realities. We evaluate the level of interactions between students and teacher and the extent to which this pedagogy influences some students behaviors. Finally, the continuation of our research is highlighted.
\end{abstract}

Keywords- Persona, Living Persona, interactive system, practical works, Human-Computer Interaction (HCI) teaching, UML

\section{INTRODUCTION}

This research effort focuses on the teaching of the specification of interactive systems, particularly in higher education [1-2]. During our many years of teaching, we observed that very often the teachings scenario was conceived mainly to achieve acquisition of knowledge and know-how. This scenario was based on the distribution of an assignment to students who must, alone or in pairs, solve the problem statement [3]. In this pedagogy the students are alone with the problem they are to solve.

This pedagogy does not include special provisions to make teaching close to professional realities. This teacher-centered approach is not well suited to improve interactions between students and teacher. It does not consider scenario linked to future work situation where students will interact with a client. The quality of the relations between the students and the teacher depends on the natural qualities of the protagonists and can therefore vary a lot. This pedagogy does not include special provisions to make students demonstrate commitment, creativity and motivation. Yet these traits are highly appreciated in the world of work.

In this paper, we propose a teaching scenario that bridges these gaps. It is based on a socioconstructivist approach valuing co-construction in context of knowledge and skills instead of transmission of decontextualized and disembodied knowledge [4]. Our pedagogy is based on the Persona technique.

The Persona technique is a technique used in the design of interactive systems or more generally products [5-6]. It complements other quantitative and qualitative methods [7] to improve the communication with the stakeholders and produce a design of high quality. A Persona is an archetypical figure and a fictional character that represents a typical user of a system. The use of Persona gives a supplement or an alternative to end user's direct involvement [8] to meet the limitations of existing means of determining the needs of users and performing high level conceptual design. The use of Personas in the design of application is well established in industry [9].

The main idea of our pedagogical approach is to derive the Persona technique used in Human-Computer Interaction (HCI) engineering to define a new pedagogical technique. Thus the paper is structured as follows. First we recall the technique of the Persona and then we propose a new pedagogical technique: Living Persona. Then we present an educational scenario integrating this new technique, and study whether the Practical Works (PW) of specification of interactive systems set up with this scenario provide students with work situations close to professional realities. Finally, we examine the extent to which the proposed scenario with the Living Persona influences the student-teacher interactions and student motivation and performance.

Our study involved three different groups of undergraduate and master's degree students from three different universities comprising 136 students. The main goal is teaching the 
specification of interactive systems, an essential skill in software engineering. Each group of students has the same topic and assignment to carry out. In order to enhance the motivation of students, we proposed a subject with a unified viewpoint, related to simulating real scale software development [10], in our case the subject is concerning a 'Smart kitchen system'. The participants had 6 hours of practical work and were asked to provide a report and answer a questionnaire at the end of the session. The students did not have the same level of knowledge on software modeling technique. Master's students had some knowledge on software design (but not on interactive software design) and practiced some modeling techniques during their learning path. Undergraduate student did not have any knowledge about interactive software design.

\section{From PERSONA TO LIVING PERSONA}

\section{A. Persona}

Originally, the term Persona comes from the ancient Greek; it designated the mask of theater actors, then the role of the actor. In his theory of analytical psychology, Gustav Jung (1875-1961) used it to designate the system of adaptation through which people communicate with the world [11-13]. In general, the Persona is the mask that every individual carries to meet the demands of life in society. Currently, the technique of the Persona consists in introducing, in the process of realization of a product, one or several fictitious personages who represent users of the product to be conceived [5-6]. The originality of this technique is that the Persona is defined by its psychological components, objectives, motivations and behaviors, rather than by demographic or social data.

Reference [5] was the first to use the Persona concept to define a technique for analyzing end-user behavior when designing an interactive system. In his technique, Cooper minimizes the involvement of users in building the Personas and uses them to promote communication among the development team. Reference [14] developed the technique by defining a 23-point method around observation and analysis of future users to produce Personas that become descriptive models of user archetypes. They are a synthesis of several people who share the same objectives, motivations and behaviors. A Persona is then defined in two parts: first a list of characteristics and then a narrative about the character [15]. Following [14] and [16], several authors, such as [17-21 have proposed various techniques to identify Personas but the Persona principle remains the same: to define one or more archetypes of users through the description of psychological components, objectives, motivations and behaviors. In the description of a Persona, it is important to specify personality traits as they can help engineers to produce designs tailored to the needs of end users [7].

In [22], the authors adapted the components of a Persona from [12] and compose their Personas considering ten components (Table 1): Identity, Status, Goals, Knowledge and experience, Tasks, Relationships, Psychological profile and needs, Attitude and motivation, Expectations, Disabilities. Details and examples of Personas with such a structure can be found in [12], [19].

\section{B. Persona in HCI education}

The use of Personas in HCI education is not new, in their original form. To teach HCI design, [23] ask their students to create Personas through pedagogical workshops. They highlight effective and bad Persona models, and present tips on how to encourage students to create good Personas. [24] use Personas to teach accessibility issues. They complete the textual descriptions of Personas by videos featuring them. They conclude that this text-video linkage is a good communication channel to increase awareness of accessibility issues and to promote the use of knowledge about accessibility in inclusive development. The Persona technique allows project stakeholders (such as designers) to identify and feel empathy for the individuals they represent [21] [25]. This particularity goes in the direction of engaging pedagogies [26] which are not based solely on mechanisms of sanctions and argumentation.

TABLE I. COMPONENTS OF A PERSONA ([12], ADAPTED From [22])

\begin{tabular}{|c|c|}
\hline Components & Description \\
\hline Identity & $\begin{array}{l}\text { Includes a first and last name, age and oth- } \\
\text { er demographic information. }\end{array}$ \\
\hline Status & $\begin{array}{l}\text { Whether the user is a primary, secondary, } \\
\text { tertiary, or anti-user of the application. } \\
\text { Typically, only primary and in some cases, } \\
\text { secondary users are included. }\end{array}$ \\
\hline Goals & $\begin{array}{l}\text { Besides goals related to the application, it } \\
\text { includes personal and professional goals as } \\
\text { well. }\end{array}$ \\
\hline $\begin{array}{c}\text { Knowledge } \\
\text { and Experience }\end{array}$ & $\begin{array}{l}\text { Knowledge and experience including edu- } \\
\text { cation, training, and specialized skills. This } \\
\text { should not be limited only to the applica- } \\
\text { tion. }\end{array}$ \\
\hline Tasks & $\begin{array}{l}\text { Frequency, importance and duration of } \\
\text { most important tasks related to the applica- } \\
\text { tion. }\end{array}$ \\
\hline Relationships & $\begin{array}{l}\text { Include information about user associates, } \\
\text { since this could give insight on other } \\
\text { stakeholders. }\end{array}$ \\
\hline $\begin{array}{l}\text { Psychological } \\
\text { profile and } \\
\text { Needs }\end{array}$ & $\begin{array}{l}\text { Include information about cognitive and } \\
\text { learning styles, as well as needs such as } \\
\text { guidance and validation of decisions. }\end{array}$ \\
\hline $\begin{array}{l}\text { Attitude and } \\
\text { Motivation }\end{array}$ & $\begin{array}{l}\text { Include information about the user's atti- } \\
\text { tude to information technology and level } \\
\text { of motivation to use the system. }\end{array}$ \\
\hline Expectations & $\begin{array}{l}\text { Information about how the user perceives } \\
\text { the system works, and how the user orga- } \\
\text { nizes information related to his/her task, } \\
\text { domain or job. }\end{array}$ \\
\hline Disabilities & $\begin{array}{l}\text { Any disabilities, such as color-blindness, } \\
\text { related to mobility, eyesight (wears con- } \\
\text { tacts), etc. }\end{array}$ \\
\hline Photograph & $\begin{array}{l}\text { Include a photograph which fits with the } \\
\text { name. }\end{array}$ \\
\hline
\end{tabular}




\section{Living Persona}

1) Living Persona in our practical work

As part of our practical work on specification of interactive systems, we have taken up the Persona concept by providing students with a description of a Persona. This description modeled the characteristics and state of mind of a personnel representative of the contracting authority concerning the system to be specified, also a future user of this system (Fig. 1). The structure chosen for our Persona came from [22] (see Table 1). The students had to take the Persona's description into account in order to propose an innovative interactive system in line with the needs and the state of mind emanating from the Persona. However, we have been pushing the innovation further as we introduce the Persona to evolve the relations between the teacher and the students. Indeed, some researchers [27] found that designers do not completely use Personas during design. They find that Personas are too [27]:

1. Abstract. Personas appear as lacking critical details.

2. Impersonal. Personas fail to provoke empathy.

3. Misleading. Some characteristics of Personas create additional constraints and are irrelevant to the design.

4. Distracting. It is difficult to determine which features of Personas are really important for the design.

To avoid this situation and ensure that our students use more and better the Persona concept, we 'have given life' to our Persona. Thus during the practical sessions, the teacher could play the role of Persona. During the practical work sessions, the students had to meet the teacher, but they had to choose the objective of the meeting:

1. Either the meeting focused on the application field (in our case the design of smart kitchens) or on the needs of the future system to be specified.

2. or the meeting focused on academic reasons, such as the form of the final report to be rendered, the technical validity of the propositions made (here UML diagrams), and so on

In the first meeting the teacher should play the role of the Persona by displaying reactions and advices conforming to its description (Fig. 1). He or she was then the Living Persona. In the second meeting, he or she adopted the classical role (as a teacher). He or she was then the classical teacher. Fig. 2 illustrates the two roles played by the teacher.

In addition, students were required to work as competing teams through a call for tenders. This last point meant that the statement did not specify all user requirements for the system to be specified. The students discussed them with the Living Persona.

\section{2) About Living Persona method}

In this subsection, we contrast our Living Persona method with Cooper's Persona method (proposed in 1995 by Cooper: Goal-Directed design process). The latter method begins with a pre-design phase. The users intervene only in this phase. At the end of it, 3 to 7 Personas are defined as well as a series of scenarios that the product to be realized has to make it possible to satisfy. Then, in the design phase, Personas are used to improve communication within the team and define an effective and relevant product [28].

Our method fits into a different context. First of all, the main goal of our method is to promote learning; so the definition of the product is not the goal in itself. Indeed, the product made by the students will not be really used. The teaching sessions are 6 hours in our case, a short period compared to a product design project that can last from a few weeks to a few months. So the following differences have been introduced:

- Only one Persona was used to provide a reasonable context for the teaching situation.

- The Persona was created by the teacher and was provided directly to the students. The students could so directly concentrate on the application of what they studied in class

- The Persona role was played by the teacher. It was a natural, lively and important part of the project.

- Often the development teams communicate the description of the Personas in the form of large posters posted on the wall to familiarize the team members with the Personas [29]. In our case the description of Persona was communicated during the distribution of the statement and was included in the LMS (Moodle) of the teaching. No posters were posted on the walls with the photo and description of the Persona. Indeed, classrooms are shared with other teachings, thus leaving posters unattented is not the best option. This practice may be changed in the future.

\section{ASSESSMENT OF THE POTENTIAL INPUTS OF THE LIVING PERSONA}

\section{A. Research objectives}

In the previous section we have presented our implementation of the Living Persona technique in a pedagogical scenario applied to teaching exercises in interactive systems. In this section, we are interested in the evaluation of this pedagogical scenario. The research questions that arise concern the pedagogical situation induced.

1. To what extent does a problem statement of practica work that used the scenario including our Living Persona technique, bring students closer to a work situation related to the professional world?

2. To what extent the interactions between students and teachers (or Living Personas) are favored?

3. To what extent does this performance influence the student behavior? 


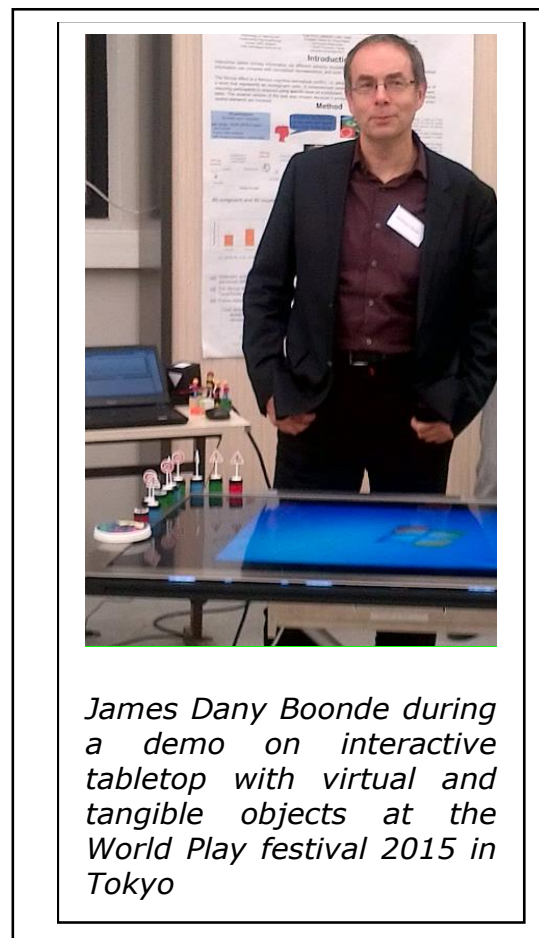

James Dany Boonde, of Planet Entertainment Inc., is available to companies responding to a call for tenders for the design of an innovative interactive kitchen system. He is 49 years old, married and has nine children ( 4 boys and 5 girls) who all love the conviviality of a good meal.

James Dany Boonde is representative both of users of the system targeted in the invitation to tenders (because his hobby is cooking), as well as analysts, designers and project managers in connection with such systems. In his various positions within the company, his aim has always been to help the company invent new systems, both innovative and profitable, allowing its users to be entertained (in the broadest sense of the term), alone or in groups. Its motto is: "Nothing beats a good user experience". But one day he witnessed an accident in connection with an innovative system of assistance for displacement (car in a ditch) and understood that any system also has to be safe for its users.

James Dany Boonde holds a Master's Degree (with distinction) in Computer Science from the University of Valenciennes, France and followed a creativity management module at Harvard University, Cambridge, Massachusetts. He rose through the ranks of Planet Entertainment Inc.

Hired as a programmer in 1990, he subsequently experienced a lot of positions, as an analyst, designer and project manager, always at the heart of innovation. He has worked in various subsidiaries of the group, both in France and abroad (Germany, United States, Netherlands and Tunisia).

As a project manager, he likes to surround himself with creative people coming from different disciplines to facilitate the brewing of ideas. It is no coincidence that his teams have deposited more than 20 patents at the international level and that he has received an Innovation Golden Globe from the INNOV'2012 show in New York in connection with a fun and personalized information system in the field of transport. Among other things, he has proposed new pedagogical simulators in the field of surgery, a card game for the blind and several applications related to interactive tabletops with tangible objects.

Even if he is appreciated for his conviviality, his colleagues know that they will always have to surpass themselves because he does not like mediocrity, or banality: each system must stand out, must bring a plus in relation to the competition. He is very demanding, but does not hesitate to spend a lot of time advising and guiding novice analysts and designers, so that they always go further in the concepts, to the service of the projects and objectives of the team.

He loves his job and spends his time looking for new ideas, for new systems, whether in nature, in cinema (especially science fiction), by observing the behaviors of people on the street, at work, in means of transport, stores, etc. He would like the new systems to be everywhere, contributing to ambient intelligence, in every room and environment, under all circumstances.

He also finds that his hearing is tending to decline over time, while noting that the population is aging in some countries. "It's a factor to be taken into account when it comes to innovation," he often says to his teams.

Fig. 1. The Persona description given to students 


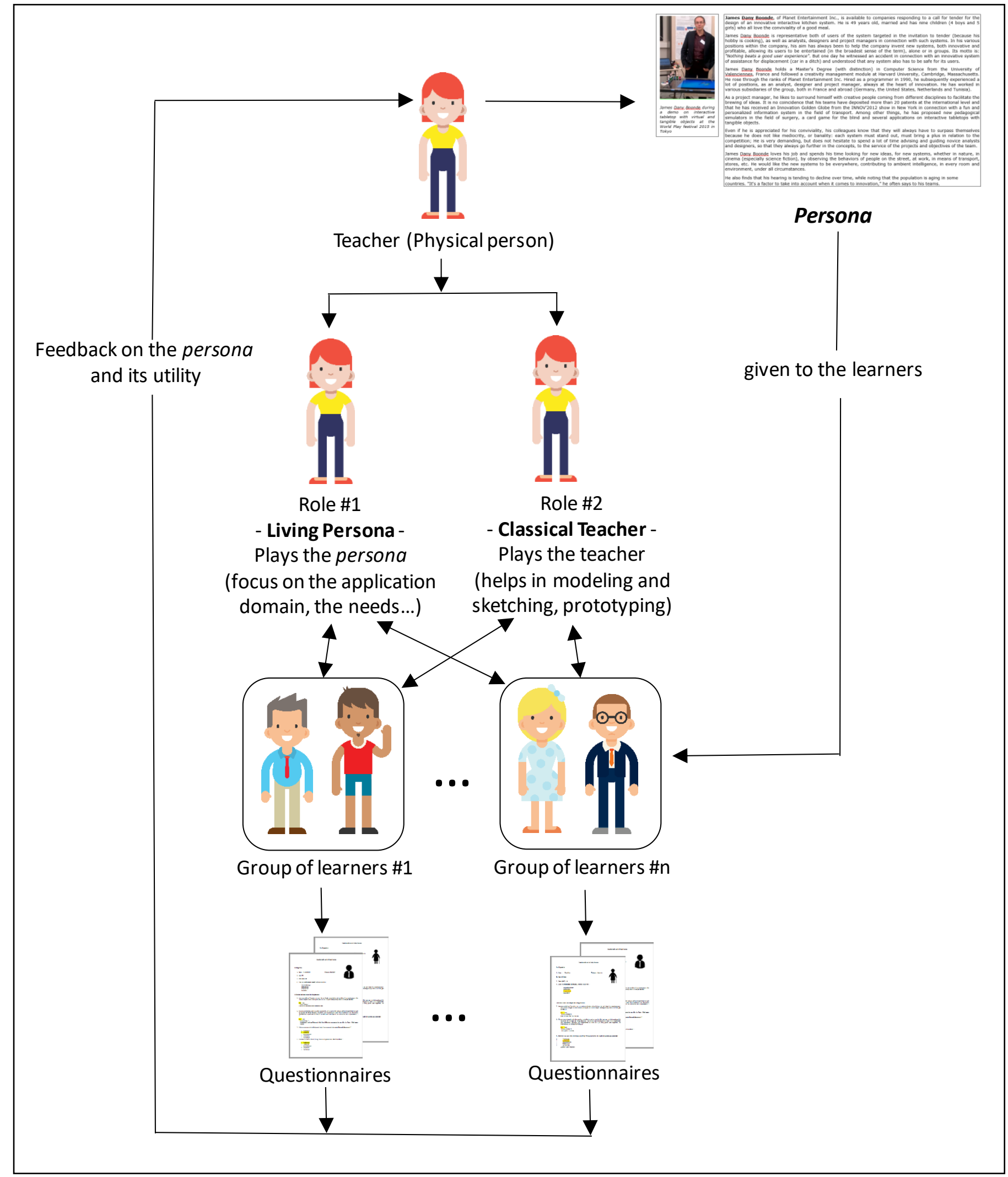

Fig. 2. The two roles of the teacher 


\section{B. Study conception}

First, we defined in the assignment a two-part problem statement. The first part set out the invitation to tender. The aim was the following:

- To "create an interactive system, easy to use for the whole family and naturally integrated in the kitchen. It should encourage people to cook healthy, affordable and delicious meals. The system also had to be specified using UML diagrams".

The second part introduced the Persona played by the teacher (Fig. 1). During the practical work, the teacher had to physically play two roles. The Living Persona role and he/she should have only answered to the questions referring to the specifications of the targeted product (an innovative kitchen). The role of teacher on the other hand should be only to answer questions of academic order.

To help distinguish both roles played by the same person, when a teacher was playing his role as Living Persona, he told students and wear a distinctive sign (a colored cap or jacket) and/or he/she changed his manner significantly to speak.

The problem statement specified that the students had to form teams with 2 or 3 students and that these teams were in competition within the framework of a call for tenders. We administered this practical work to 136 students distributed in three different groups in three different universities:

- Two groups concerned first-year students of IT Master's degree (graduate) whose mean age was of 23,01 years. For this group, the public consisted of 81 students among whom 8 women.

- The third group concerned first academic year (undergraduate) students in computing, the average age of which was of 18,7 years. For this group, the public consisted of 55 students among whom 3 women.

Each class has had 6 hours of instruction taught in practical work. At the end of practical work, the students had to answer a questionnaire of 15 questions among which 8 questions concerned the appearance of criteria met during professional situations. The answers and the justifications to the questions 1,2 and 6 were related to the first research question. The answers and the justifications to the questions 3 and 4 were related to the second research question. The answers and the justifications to the questions 5, 7 and 8 had to answer the third research question. For each question (possible responses: yes/no), a written justification was requested from the students. These eight questions are:

1. Do you think that this technique of the Living Persona enables to make the problem statement more concrete?

2. Do you think that the role of Living Persona is similar to the role of a client?
3. Do you think that this technique of the Living Persona favors the number of interactions with the teacher?

4. Do you think that this Living Persona technique promotes the quality of interactions with the teacher?

5. Do you think that this Living Persona technique promotes engagement in your team?

6. Do you think that this technique of Living Persona makes the problem statement closer to the professional situations that you will encounter once in the labor market?

7. Do you think that this technique of Living Persona has fostered the creativity of the team?

8. Do you think that this technique of Living Persona motivated you?

The results presented below are based on the answers to the questionnaires filled in by the students at the end of the course, their written justifications and the observation of the students' work during the practical sessions.

\section{RESULTS AND DISCUSSIONS}

\section{A. Validity and risks}

Before discussing the answers to all the questions, we asked the students if the teacher played well his/her role of Living Persona. Otherwise the study should not be interesting. $97,6 \%$ of all the 136 students surveyed estimated that the teacher played well or very well his/her role of Living Persona. This role matched to the description done in the problem statement and helped students to elaborate their technical solution.

In the questionnaire we asked them if they have appreciated the learning scenario including the Living Persona. They were $92,91 \%$ to appreciate the Living Persona technique in particular because the pedagogical situation was closed to the actual work situation and was original. These results, presented in the next paragraph, showed that the practical work session conformed to the objectives of the study and to the learning scenario defined in Section II.

\section{B. Results}

Table 2 presents the results of the eight questions we asked to the students. These results are displayed in decreasing order of satisfaction. The results point out that the students found that the learning scenario based on the Living Persona enabled them answer positively to our three research questions.

However, in the next paragraphs, these initial results will be nuanced. Generally speaking, the positive influence of the scenario cannot be disputed. The criterion «engagement in the team ", the least supported criterion, gathered near two thirds of satisfaction. 
TABLE II $\quad$ RESULTS IN ORDER OF SATISFACTION

\begin{tabular}{|l|c|c|}
\hline \multicolumn{1}{|c|}{ Criterions (questions) } & Yes (\%) & No (\%) \\
\hline Work situation (q6) & 93,97 & 6,03 \\
\hline Client role (q2) & 90,08 & 9,92 \\
\hline Concrete work (q1) & 89,55 & 10,45 \\
\hline Interactions quality (q4) & 74,42 & 25,58 \\
\hline Causes the motivation (q8) & 73,28 & 26,72 \\
\hline Number of interactions (q3) & 72,93 & 27,07 \\
\hline Creativity of the team (q7) & 71,21 & 28,79 \\
\hline Commitment to the team (q5) & 64,62 & 38,38 \\
\hline
\end{tabular}

\section{Discussions}

\section{1) First research question}

From all the students' feedback, the strongest feeling is that the pedagogical situation experienced is closed to the professional reality. For $94 \%$ of the students, the Living Persona technique provides a problem statement very close to the business reality (Table 2, first line). Written comments put forward by students confirm this result. The next three comments are representative of those expressed by most of the students.

"This Living Persona confronted us to the precise tenders of a project manager, which can be a possible professional situation in our future work. This prepared us to such situations and give us foretaste of the labor market"

"This project is much closer to reality: client contact, team work, task division, constraint to respect, etc.".

"I think that this technique of Living Persona helps to make the problem statement closer to real business situations that we will experience when facing a client to whom we must offer a product that meets his/her expectations."

For $90 \%$ of the students, the scenario process based on the Living Persona enabled them to cope with a client tastes, needs and expectations (Table 2, line 2). Similarly, for $90 \%$ of the students, the scenario process based on the Living Persona has made it possible to arrive to a concrete business situation (Table 2, line 3). The next three comments, representative of those expressed by the students confirm this.

"The concept of Living Persona had allowed to us make the project more concrete by placing us in the position of a company with the aim of satisfying the needs of a client. This encourages us to conduct a project in a more serious manner and more professionally approach."

"I think sincerely that this technique of Living Persona makes the problem statement more concrete as it keeps the project alive and confronte each of the member of project team to real situations and constraints met in a professional experience». "

"This technique makes the problem statement more concrete as it can «simulate » a client and be as close as possible to real-work situations where we will not have to interact with a teacher but with clients."

These results would justify an affirmative answer to our first research question. They are the most important results of our inquiry. The response rate ranges between $90 \%$ and $94 \%$. Our study shows that the strongest feature of our scenario based on the Living Persona is to place students in a situation very close to the realities of the workplace. Vocational guidance for students and the analysis of the written comments have concluded that students effectively live through the establishment of a situation close to realwork situations.

\section{2) Second research question}

With $74 \%$ of positive responses concerning the quality of interactions (Table 2, line 4) and 73\% for the number of interactions (Table 2, line 6), students expressed the view that the proposed scenario promotes the quality and number of interactions with the teacher (for his/her two roles: traditional teacher and Living Persona). The analysis of the students' written comments and the session's program create a more living and interactive scenario than in the traditional class work practice. The next three comments are representatives of those expressed by the students.

"The Living Persona system allows us to go further in our researches thanks to the role played by the teacher. Through this role, we can ask questions to the teacher we do not dare to ask without this system."

"The fact of playing a role, allows both the student and the teacher to have interesting and constructive discussions, until the student is serious and disciplined about his/her role of course."

"Yes, I think that this technique of Living Persona results in higher quality of interactions with the teacher since we have to meet him/her as a client and not as a teacher."

However, some students qualify this result. They say that quality and number of interactions depend on the teacher and on the Living Persona. Some students state this fact in their written comments.

"The quality of interactions does not depend on this technique, but on the teacher and the student." 


\section{3) Third research question}

For this research question, we are limited to three principal attitudes in the specific context of HCI design and in other general professional cases, which are motivation, creativity, and engagement of the team. The results presented in Table 2 show that the impact of the Living Persona technique stay at a high level (but lower compared to the results of the previous research questions): $73 \%$ of the students opt for motivation, $71 \%$ for better creativity and $64 \%$ for better engagement in the team (Table 2, lines 5, 7 and 8).

In addition, the justifications of the students point out regularly that other characteristics of the learning situation influence their behavior (team work, delay, rating of the work and competitively between team). We found some comments illustrating this fact.

"It is not necessarily the Living Persona technique that will motivate us but the team work and the concrete subject."

"Yes, I believe that this technique motivated me only for the deadline to propose a solution to the client."

"To be in group and being able to interact with a professional help us to move ahead, and therefore motivates us."

"I have a huge competitive spirit. It is not enough if I am not the first one in what I consider to be my area of responsibility. So yes, competition between work groups has really made me to surpass myself to find original ideas that different from others and more generally ideas that work in practice. Last year, our practical work was nothing more than diagrams designed on the whiteboard of the classroom in such a boring way that I did not want to come to the classroom. Whereas with this technique, I was surprised not to see the time pass when I was working on the project."

\section{4) Other findings}

In the margins of the research questions, the analysis of the student's justifications shows an unintended contribution of the learning scenario proposed. In fact, they believe that the Living Persona has produced significant improvements of the relationships with the teacher. The technical aspects of UML modeling are discussed with the teacher in his/her classical role while the user's needs are being addressed with the Living Persona.

On the other hand, although this is the same person who plays the Living Persona and the classical teacher role, they find the contact with the Living Persona less intimidating. In the following, we list some other comments illustrating this fact.
"Students are less afraid to ask for information to the Living Persona than to the teacher, knowing that it won't be negatively perceived."

"The Living Persona makes us also fall on a role and eliminates traditional barriers between students and teachers; it makes you want to interact to study certain questions even further."

"We can ask some questions when he/she is in the role of client and others when he/she is in a teacher role. The context is clearer."

"Yes, because we now know what to ask to the client and what to ask to the teacher. The difference between the two roles helped us see with greater clarity our work."

A feedback often expressed by students is that when the teacher plays the role of Living Persona, he/she must make sure to remain concrete in his/her interactions and above all keep distance from his/her traditional role as a teacher. This issue is more sensitive as the Living Persona was defined as someone who studied HCI design (Fig. 1) and some students asked for technical questions to the Living Persona.

Some students would have preferred that two different actors would play the two roles but it was not possible due to economic reasons.

\section{CONCLUSION AND PERSPECTIVES}

This paper proposes a new pedagogical technique: the technique of Living Persona. It is an evolution of the popular technique of the Persona, initiated by [5] in the field of the HCI. Then we integrated this technique as a central element of a scenario where competing teams of students had to realize a specification of interactive systems written in the UML language. The teacher had to play two roles: (1) A client who had to adopt a precise state of mind, that of the Persona (provided to the students); (2) A traditional teacher who had to accompany the teams from an academic point of view (application of the UML language, technical constraints on the work to be done in terms of volume, form, delivery date, etc.).

We tested this approach with 136 students separated in three different groups. The answers given to the given questionnaires and their justifications highlight the interest of the proposed scenario which creates a situation close to professional realities (lines 1 to 3, Table 2). The answers also reveal good results related to quality interactions and in large numbers (lines 4 and 6, Table 2). Last but not least, the answers also illustrate the positive outcomes regarding students' behaviors but somehow not related to their development of their professionalism (lines 5, 7 and 8, Table 2).

However, the figures suggest that the proposed scenario is more effective in creating conditions close to professional realities than in developing professional behaviors among 
students. Indeed, the first three most popular criteria for students concern working situations and receive satisfaction close to or above $90 \%$. The last five criteria relate to students' interactions and professional attitudes and are relatively less satisfactory, as they range from $75 \%$ to $65 \%$ satisfaction.

In the future, we plan to improve the scenarisation in particular by highlighting the competition between teams. It will also be interesting to put our results in perspective according to the level of training of the students. In fact, two classes were attended by 81 students in the first year of graduate students and a class of 55 undergraduate students. We will also improve the survey using a Likert scale instead of binary responses.

\section{REFERENCES}

[1] Hewett, T., Baecker, R., Card, S., Carey, T., Gasen, J.,Mantei, M., Perlman, G., Strong, G., and Verplank, W. 1996. "Curricula for human-computer interaction". http://sigchi.org/cdg/.

[2] Talon, B., Sagar, M., and Kolski, C., "Developing competence in interactive systems: The GRASP tool for the design or redesign of pedagogical ICT devices". ACM Trans. Comput. Educ. 12, 3, Article 9 (July 2012), 43 pages.

[3] Warin, B., Kolski, C., and Sagar, M., "Framework for the evolution of acquiring knowledge modules to integrate the acquisition of highlevel cognitive skills and professional competencies: Principles and case studies", Computers \& Education, 57,1595-1614, 2011.

[4] Jonnaert, P., "Compétences et socioconstructivisme : un cadre théorique", De Boeck supérieur, 2002.

[5] Cooper, A., 1999. "The Inmates are running the asylum: why hi-tech products drive us crazy and how to restore the sanity", Macmillan Publishing Co., Inc, Indianapolis, IN, USA, 1999.

[6] Cooper, A., "The origin of Personas", Last accessed on May 12, 2017 at https://www.cooper.com/journal/2008/05/the origin_of_personas.

[7] Anvari, F., Richards, D., Hitchens, M., Ali Babar, M., Thi Tran, H.M. and Busch, P., "An empirical investigation of the influence of persona with personality traits on conceptual design", The Journal of Systems and Software 134, pp. 324-339, 2017.

[8] Gould, N., and Atkin, D., "Towards a semantic layer to support road and public transport user decision-making". In: Computer and Information Technology; IEEE International Conference on Ubiquitous Computing and Communications; Dependable, Autonomic and Secure Computing; Pervasive Intelligence and Computing (CIT/IUCC/DASC/PICOM), pp. 1498-1503, 2015.

[9] Miaskiewicz, T. and Kozar, K.A., "Personas and user-centered design: how can personas benefit product design processes". Des. Stud. 32 (5), pp. 417-430, 2011

[10] Tamai, T., "How to teach software modelling", ICSE'05, May 15-21, 2005 St Louis, Missouri, USA, ACM p. 609-610, 2005.

[11] Jung, C. G., and Jaffé, A., "Memories, dreams, reflections", New York, Random House, 1965.

[12] Seffah, A., Kolski, C. and Idoughi, D., "Persona comme outil de design de services interactifs : principes et exemple en emaintenance". Proceedings of IHM 2009, 21ème Conférence de l'Association Francophone sur l'Interaction Homme-Machine (Grenoble, France, 13-16 october 2009), ACM, pp. 333-336, 2009.

[13] Ruault, J. R., Kolski, C., and Vanderhaegen, F., "Persona pour la conception de systemes complexes résilients", Proc. ERGO-IHM, 2012.

[14] Pruitt, J., and Grudin, J. J. "Personas: practice and theory". Proc. Designing for User Experiences, DUX'03, ACM Press, 2003.

[15] Acuña, S.T., Castro, J.W. and Juristo, N., 2012, "A HCI technique for improving requirements elicitation", Information and Software Technology 54 (2012) pp. 1357-1375, 2012.
[16] Brangier and E., Bornet, C., "Persona: A Method to produce representations focused on consumers' needs", In W. Karwowski, M Soares \& N. Stanton (Eds.). Human Factors and ergonomics in Consumer Product Design. Taylor and Francis, pp. 38-61, 2011.

[17] Costa, A.C., Rebelo, F., Teles, J. and Noriega, P., "Child-persona: how to bring them to reality? ", 6th International Conference on Applied Human Factors and Ergonomics (AHFE 2015), Procedia Manufacturing 3, pp., 6520 - 6527, 2015.

[18] Nielsen, L., Personas-user focused design. HCI Series, Springer, 2013.

[19] Idoughi, D., Seffah, A., and Kolski, C., "Adding user experience into the interactive service design loop: a persona-based approach", Behaviour \& Information Technology, 31:3, pp. 287-303, 2012.

[20] Schäfer, C.Zinke, R., Künzer, L., Hofinger, G., and Koch, R., "Applying Persona method for describing users of escape routes", The Conference on Pedestrian and Evacuation Dynamics, Transportation Research Procedia 2, pp. 636 - 641, 2014.

[21] Vosbergen, S., Mulder-Wiggers J.M.R., Lacroix J.P., Kemps H.M.C., Kraaijenhagen, R.A., Jaspers, M.W.N., and Peek, N., "Using Personas to tailor educational messages to the preferences of coronary heart disease patients", Journal of Biomedical Informatics, 53, pp. 100-112, 2005.

[22] Courage, C., and Baxter, K. "Understanding your users: a practical guide to user requirements methods, tools, and techniques". Elsevier, San Francisco, CA, 2005.

[23] Jones, M.C., Floyd, I.R. and Twidale, F.M.B., "Teaching design with Persona", Interaction Design and Architecture(s) Journal - IxD\&A, N. 3-4, pp. 75-82, 2008.

[24] Loitsch, C., Weber, G., and Voegler, J. (2016, July). Teaching accessibility with Personas. In International Conference on Computers Helping People with Special Needs (pp. 453-460). Springer International Publishing.

[25] Pruitt, J., and Adlin, T., "The Persona lifecycle: keeping people in mind throughout product design", In Morgan Kaufmann Publishers Inc. San Francisco, CA, USA, 2005.

[26] Witchel, H.J., Santos, C.P., Ackah,J.K., Tee, J., Chockalingam, N., and Westling, C.E.I., "The complex relationship between empathy, engagement and boredom", September 2016, ECCE '16: Proceedings of the European Conference on Cognitive Ergonomics.

[27] Matthews, T., Judge, T., and Whittaker, S. , "How do designers and user experience professionals actually perceive and use personas?" In: Proceedings of the SIGCHI Conference on Human Factors in Computing Systems : ACM, pp. 1219-1228, 2012.

[28] Blomquist, $\AA$ and Arvola, M., "Personas in action: ethnography in an interaction design team". In: Olav W. Bertelsen (Ed.), Proceedings of the Second Nordic Conference on Human-Computer Interaction 2002, Aarhus, Denmark, October 19-23, ACM, pp. 197-200.

[29] Gu ðjónsdóttir, R., and Lindquist, S. , 2008. "Personas and scenarios: design tool or a communication device?" In: 8th International Conference on the Design of Cooperative Systems , Carry Le Rouet, France, pp. 165-176, 2008. 